\title{
Birth and Research of Erhu Concerto
}

\author{
Jindi Zhang
}

Art College, Shandong University, Weihai, 264209, China

\section{Keywords: Erhu; Concerto}

\begin{abstract}
Erhu concerto is a type of music which was born under integration of Chinese and western cultures. It is one of the most typical solo concertos in Chinese national musical instruments. Since the establishment of new China, Erhu concerto has developed rapidly. It gained different development in four historical periods: before the reform and opening-up, 1980s, 1990s and the 21st century. Erhu concerto generates significant influence on development of Erhu music and occupies an important position in development history of Erhu music.
\end{abstract}

\section{Birth of Erhu concerto}

Since the $20^{\text {th }}$ century, Erhu concerto born under multi-culture development is a kind of new music expression form. It derives from European music, but is different from European music.

In 1930s, Erhu divertimento The Death of Yang Yuhuan created by Russian Jewish composer AapoHABUiajiyMOB (1894-1965) consists of 6 songs and adopts the form of Erhu and symphony orchestra. This is the earliest Erhu concerto recorded in the history and originated from the melody of self-created song Evening Scene of Ynag Yuhuan in 1936. In Yearbook of Chinese Music (2002), Mr. Zheng Tisi said in his memoirs that, this works was performed in public in Shanghai Lanxin Theater. The band was Shanghai Municipal Council Orchestra. The outstanding folk music performer Mr. Wei Zhonglei took charge of Erhu solo, and the composer was responsible for commanding. Such manifestation pattern of Erhu music was certain far-sighted in the development of world music and also reflected world culture had walked out of European cultural circle and went to other developing countries. China - a country with an ancient civilization experienced the period from prosperity to decline. In the $20^{\text {th }}$ century, it became the development center of new world culture. This also indicated that Chinese music culture would be impacted by world culture and would enter a huge culture revolution period. In this culture revolution period, revolution and development of music culture would experience a washing and depositing process. Really pure music culture was filtered through time.

At the beginning of the $20^{\text {th }}$ century, China's Royal court music, scholar-bureaucrat music and organizations died out as the royal court perished and the court disintegrated or flowed to the folk. China's folk music could not meet aesthetic demands of students and scholar-bureaucrats under the influence of new ideological culture, so it was considered to be vulgar and obscene music. China at that time was in the turbulent period of political transformation. Meanwhile, the development of national development was also influenced by the current political situation and was in the decline period of temporary shortage. At that time, some music persons with the experience of studying abroad and radical idea saw current situation of national music. Compared with national music in European countries, Chinese national music was barely satisfactory in the following aspects: musical instrument manufacturing, tone quality and tone, tone uniformity and richness degree of combined musical instruments, performed tone, rhythm standard and unification as well as music effect and art quality. Wu Bochao familiar with traditional Chinese music and studying western music considered, "Chinese national music school" which could be comparable to various countries in the world could be established only through creating a large number of professional works with perfect art quality. Mr. Zhu Ying had the similar opinion with him and proposed that in order to meet the urgent need of national music, firstly, it was necessary to create new works through referring to creation expere4ince and methods of Chinese national music or using techniques and spirit of western music. So, he stressed "those studying national music must research composition". 
The first half of the $20^{\text {th }}$ century, emerging national music development increasingly tended to a mighty music development situation. The improvement ways if national music was sought between firmly sticking to the quintessence of Chinese culture and wholesale westernization to make national music revitalized.

In about 1930s, people in Shanghai music circle organized the funfest which organized 2 special performances and more than 20 traditional stringed and ensemble playing with woodwind instruments recomposed according to archaic music under the thought guidance of firmly sticking to national music. These practices of revitalizing ancient music lacked injection of new blood and was thus submerged in the tide of learning from the west.

In the same period, "national band" was also organized in another political place - Chongqing. This is the first new and professional national orchestra with certain scale in historical records. Before the establishment of new China, the band created and recomposed large quantities of Chinese works with new form and new appearance.

\section{Classification of Erhu concerto}

The world "concerto" stemmed from Latin "collcertaye”. Its original meaning was competition and cooperation, i.e. "competition", “consistency" and "acoustic resonance”. At the earliest, the concerto was music accompanied with musical instrument and was born in Italy in the $16^{\text {th }}$ century. It developed to instrumental music divertimento in the $17^{\text {th }}$ century. One or more solo musical instrument(s) competed to play with orchestra. In Baroque period, concerto developed to concerto grosso. Several solo musical instruments formed a group and competed with the band. In classical music period, it developed to "solo concerto". The violin or piano competed with the band. In romantic music period, composers Haydn, Mozart and Beethoven composed large quantities of solo concerto works. Concerto is generally composed of three movements. The front and rear movements contrast and echo: the first movement is allegro of sonata form; the second movement is lyric adagio which changes the tone; the third movement is allegro which restores the tone and often adopts rondo. Hungarian pianist and composer Liszt broke traditions and adopted the form of "compressing" each movement to create single-movement works. And, sole and band accompanied each other and formed resonant intimate connection, which further drove concerto development and became a favorite music form.

Concerto also sought development in changes in different periods. It transformed to instrumental music works from vocal works, to several musical instruments from one musical instrument and to one movement from 3 movements and 4 movements. In different periods and diverse national cultures, different composers had brand-new interpretations and expressions. However, no matter how composers referred and used concerto and no matter how concerto developed, a core spiritual component kept unchanged - "concertato". Even today, people like concerto out of the reason of "concertato" and auditory sense impact it brings, rather than out of the reason of concerto's structure, main musical instrument or the band. This is because music is felt through hearing. The author considers to cognize and study concerto, it is first necessary to take into account of its most direct effect on people - music transmission.

In order to interpret the application of concerto in Erhu works and classy Erhu concerto, firstly, other musical instruments may be considered as concertato objects except the band in accordance with auditory sense feeling; secondly, considering Erhu is a Chinese musical instrument, the concerto form should take into account of music aesthetics habit of Chinese nation. In fact, Chinese music works have considered this. However, in terms of works classification, this is not considered in a systematic way. There is still no uniform works classification standard. Based on some data about current situation, creation features, sound features and initial creation features as well as comparison of congenetic works, some Erhu and piano works may be regarded as the scaled-down version of Erhu concerto during studying the development of Erhu concerto, such as Sanmen Gorge Rhapsody and North Henan Ballad. 
In the article of Qiao Jianzhong Reading Autumn Feeling - initial cognition of Wu Bochao's old Erhu works, he expressed new views on Erhu works Autumn Feeling published by Wu Bochao on Music Art in 1931 and mentioned it was the first Erhu sole with piano accompaniment. New music just started in new China. This song has several breakthroughs. Firstly, the song name is rich in romantic color, which reflects general literature significance. Compared with his teacher's names of works, it has more imaginary space. Secondly, in terms of writing conception of the works, melody conception and accompaniment conception are an integral conception and are synchronous. This is the first trial writing of Erhu and piano music. The author more considered piano conception. Obviously, the melody conception was constrained by piano. Meanwhile, influenced by European harmony, polyphony writing and other western music culture, the author used a brand-new form to create. It was very hard to skillfully master the music. Although the works still needs to be polished, it took into account of concerto problem among musical instruments and sound effects. In that era, this works was very advanced in the form and conception. Compared with Lu Huabo who purely accompanied the works of Liu Tianhua, it more approaches the conception of symphony writing. This generated motivation for later Erhu and piano symphony writing.

At present, Erhu concerto classification still needs to be standardized. In reality, everyone holds different opinions. Indeed, it is very difficult to clearly distinguish mixed use of some works. In a strict sense, Erhu concerto should own basic musical form components: one or more movements need to contain sonata form and roundelay as well as concertato form. However, actually, confused use phenomenon exists. Erhu concerto Red Plum Capriclo is taken as an example. The framework of the song is according to development logic of traditional songs. There is no sonata form in musical form structure. Based on song name and genre analysis, it is classified into the caprice of Erhu and band form, which is more proper than Erhu concerto. Lanhuahua Ballade and Parting of the Newly-married Couple should also be classified into ballade of Erhu and band form. The First Erhu Rhapsody should be classified into rhapsody. But because songs are accompanied by the band, numerous people call them Erhu concerto. Erhu works classification remains further researches.

\section{Definition of Erhu concerto}

Before China's national symphony orchestra was established, there was only small-scale band combination in terms of Chinese instrumental music. For some local bands such as Jiangnan string and pipe ensemble or Guangdong music and northern local bands, the scale is small. In particular, Huqin series use different pitches to generate polyphony concerto effect. The shape, size and tone of the same kind of musical instruments are not uniform. For example, Erwquanqin is larger than Erhu. The tone is thick and solid and the pitch is lower than Erhu. But compared with Zhonghu, it is smaller. Gaohu in Guangdong music is smallerthan Erhu, and the tone is higher. These are subject to the needs of music tone. These Huqin series had no detailed name differentiation before professional bands were set up, and the songs were also not subdivided to musical instrument performance classification.

Later, Mr. Gan Tao proposed to try to make Huqin band series of musical instruments when "national band" was established, and fix "A sound" as one of pitches of string instruments to solve sound calibration problem of a band. In this way, Huqin series has uniform pitch standard. Meanwhile, the name of Huqin has explicit difference. After the songs become more and more, Huqin family is subdivided into Gaohu, Erhu and Zhonghu etc.

Huqin series has differences in tone and there is still all-purpose phenomenon in music. The tone has no clear definition. For instance, The Great Wall Capriccio used the special Great Wall string. The tone and pitch are lower than Erhu. The Moon Over a Fountain adopted special Erquanqin and Erquan string. The tone and pitch are lower than Erhu. But these musical instruments and songs are subordinate to Erhu. For example, Zhonghu song On the Grassland could be exchanged with Erhu in terms of performance skills. In terms of tone of musical instrument, Zhonghu approaches Erhu. Meanwhile, Erhu also has abundant Mengfeng songs. In the hands of performers and the mind of the public, this becomes a conventional approval. So, Zhonghu has no specific style and performance. And its songs should be classified into Erhu. For instance, Erhu is often used to play Gaohu song The 
Palm-leaf Beated By Raindrop. Hut Gaohu is a leading musical instrument of Guangdong music. Gaohu music has forms a system with regional aesthetic features. It differs from performance features and tone of Erhu. Besides, Gaohu music has formed style classification and become a characteristic category in people's performance, auditory sense and heart. Therefore, Gohu music should be classified independently. For example, before specially-made Erhu and electro-acoustic Erhu fail to form large branches, they still are classified into Erhu.

Based on the above, for definition of Erhu concerto, the author considers in line with conventional acceptance and aesthetic habits, the works of Erquanqin, Zhonghu, specially-made Erhu and electro-acoustic Erhu can be classified into Erhu. Erhu concerto should cover concerto of these musical instruments.

\section{Research status and research significance}

The researches on Erhu concerto almost only involve works analysis, Erhu performance skills as well as materials of composers and performers, and aim at a works or a figure. For instance, Performance of Piano and Erhu concerto North Henan Ballad and specie analysis (Pan Jin), Study on Taiwan modern national music works Erhu Concerto (Xu Zhuoting) and creation thought and art features of Erhu concerto The Ballad of Mulan (Duan Xuejun) mainly conduct theoretical analysis of performance art, creation background and musical form structure. The articles aiming at development history and art features of Erhu concerto are few, and research perspective is single. For example, Ye Xiaojuan's Analysis of China's Erhu concerto development mainly classifies the works according to the style from the perspective of Erhu concerto development and sets forth content form. Hou Taiyong's Study on Erhu concerto creation in 1980s also aims at music creation in this period. There is no article organizing, excavating, studying and reviewing concerto in new China. Thus, this paper deeply explores this topic so as to improve theoretical research of Erhu art and promote scientific and systematic development of Erhu art.

\section{References}

[1] Yang Qing, Cai Meng, Exploraiton track of Chinese national instrumental music in initial creation period (II), Music Studies, 2009.1 (1), p68.

[2] Zheng Tisi, Historical review of music group of Central Broadcasting Station - birth and development of China's first new and professional naitonal orchestra, Yearbook of Chinese Music 2002, Shandong Arts Press, 2005, recorded in Reminiscence of Parties Concerned. 